\title{
Formação de professores de ciências: percursos avaliativos mediados pelo portfólio
}

\author{
Crisna Daniela Krause Bierhalz \\ Liziane Padilha Mena \\ Vitor Garcia Stoll
}

\section{Resumo}

Este artigo relata uma experiência conduzida na disciplina Prática de Avaliação Com base na concepção de avaliação formativa, tendo o portfólio como instrumento mediador, o presente estudo visa identificar a menção a concepções de avaliação da aprendizagem no Projeto Pedagógico de Curso e analisar a experiência dos professores em formação com a avaliação formativa mediada pelo portfólio. A pesquisa qualitativa foi estruturada em duas etapas, sendo a primeira a análise do PPC da Licenciatura em Ciências da Natureza de uma universidade pública da região da Campanha gaúcha, seguido da análise dos questionários respondidos por onze licenciandos que cursaram a disciplina de Práticas Pedagógicas VII e que vivenciaram o processo avaliativo mediado pelo portfólio. Entre os resultados é possível destacar que das 52 disciplinas do PPC, oito trazem em suas ementas aspectos relacionados à avaliação e duas tratam diretamente do portfólio. Em relação a concepção avaliativa do portfólio é entendida como formativa, principalmente pelo favorecimento da auto avaliação. Em relação a aplicabilidade do portfólio na futura prática consideraram viável, ressaltando a dificuldade com a escrita. Conclui-se que as concepções dos licenciandos acerca dos processos avaliativos mediados pelo portfólio e as possibilidades de ressignificação das práticas na formação inicial torna-se um desafio, pois é preciso considerar que a realidade investigada é apenas um recorte de uma totalidade ampla e complexa, sendo necessário considerar aspectos únicos de cada realidade.

Palavras-chave: Avaliação formativa; Portfólio; Formação de Professores. 


\title{
Training of science teachers: portfolio-mediated evaluation trails
}

\author{
Liziane Padilha Mena \\ Crisna Daniela Krause Bierhalz \\ Vitor Garcia Stoll
}

\section{Abstract}

Based on the conception of formative evaluation, having the portfolio as a mediating instrument, the present study aims to identify the concepts of evaluation of learning in the Pedagogical Project of Course and to analyze the experience of the teachers in formation with the formative evaluation mediated by the portfolio. The qualitative research was structured in two stages, the first being the PPC analysis of the Degree in Natural Sciences of a public university in the region of the Camacho gaúcha, followed by the analysis of the questionnaires answered by eleven graduates who studied the discipline of Pedagogical Practices VII and who lived the evaluation process mediated by the portfolio. Among the results it is possible to emphasize that of the 52 disciplines of the PPC, eight present aspects related to the evaluation and two deal directly with the portfolio. In relation to the evaluation conception of the portfolio is understood as formative, mainly by favoring the self evaluation. Regarding the applicability of the portfolio in the future practice considered feasible, highlighting the difficulty with writing. It is concluded that the conceptions of the licenciandos about the evaluation processes mediated by the portfolio and the possibilities of re-signification of the practices in the initial formation becomes a challenge, because it is necessary to consider that the investigated reality is only a cut of a wide and complex totality, being necessary to consider unique aspects of each reality.

Keywords: Formative evaluation; Portfolio; Teacher training. 


\section{Palavras iniciais}

A escrita deste texto, parte da compreensão de que cada sujeito constrói seu percurso formativo a partir de diferentes vivências, entre elas, as relacionadas aos espaços formais, como a escola e a universidade, considerando a inconclusão ou inacabamento do sujeito defendido por Freire (1981). Nesta perspectiva cabe pensarmos sobre como as Licenciaturas constroem espaços formativos críticos, reflexivos, em que estão imbricados as discussões sobre avaliação da aprendizagem e os instrumentos avaliativos.

A utilização da avaliação formativa, como estratégia reflexiva, proporciona informações acerca do desenvolvimento de um processo de ensino e de aprendizagem, com a finalidade de acompanhar as necessidades dos diferentes sujeitos que dela participam. Com este embasamento é preciso ressignificar a compreensão de avaliação, fortemente arraigada nas práticas pedagógicas tradicionais, na qual se evidencia uma preocupação maior com a classificação (notas, conceitos), do que com a construção de conhecimentos ao longo do processo, no qual são consideradas as características individuais e os interesses coletivos dos estudantes, no sentido de valorizar a aprendizagem colaborativa de todos, em diferentes tempos e de diferentes maneiras. (MARTINEZ, 2009).

A avaliação formativa, que pode ser definida como "a prática da avaliação contínua que pretende melhorar a aprendizagem em curso" (PERRENOUD, 1999), se consolida através do acompanhamento da aprendizagem do aluno tanto pelo professor como pelo próprio aluno (HERNÁNDEZ, 1998; PERRENOUD, 1999; HADJI, 2001). Esta perspectiva é ressignificada pela reflexão-na-ação e pela reflexão-sobre-a-ação (SCHÖN, 2000), ancorado nos princípios de aprender (buscar novas informações), de aprender a aprender (refletir sobre procedimentos de aprendizagem) e de aprender a ser (refletir sobre si próprio enquanto aprendiz)" (HOFFMANN, 2001, p. 139).

Quando se menciona a reflexão, não se trata somente de contar histórias e ressaltar momentos significativos, mas ir além, compreendendo como e porque aqueles momentos tornaram-se significativos e de que forma contribuíram/contribuem na construção identitária. Este movimento supera as atividades cotidianas de transmissão de conhecimentos, pois está ancorado na investigação, na qual o professor é pesquisador de sua prática, valorizando a pessoa, a sala de aula e a escola como sujeitos/lugares privilegiado de produção de saberes. Villas Boas (2006) tem estudado "a importância da avaliação formativa no processo de formação de professores, para que, como consequência, ela seja praticada em todas as escolas de todos os níveis". Para a pesquisadora, os professores aprendem a avaliar, enquanto se formam, vivenciando a avaliação e menciona a importância da autoavaliação para o desenvolvimento da autonomia intelectual.

Corroborando as ideias de Villas Boas (2006) compreendemos que as práticas 
pedagógicas e a identidade dos docentes em formação são construídas a partir de intensas negociações, através das quais negam e afirmam características em meio aos discursos e modelos apresentados a respeito da docência. O ser e o fazer docente são construídos na articulação entre as condições efetivas de trabalho, os discursos relativos à docência e as vivências pessoais.

A reflexão sobre as práticas avaliativas formativas, bem como os instrumentos de avaliação devem ser fomentados durante a formação do professor, pois trata-se de uma oportunidade de experimentar, testar, conhecer, preparando-o para o papel de orientar, criticar e desafiar aos alunos e a si mesmo no futuro. Neste sentido, no sétimo semestre da Licenciatura em Ciências da Natureza, na disciplina de Práticas Pedagógicas, são utilizados os portfólios como instrumento mediador do processo reflexivo de construção do conhecimento, evidenciando a partir dos diferentes registros quem são estes sujeitos e como se constroem professores (ARAUJO; ALVARENGA, 2006).

O portfólio é um instrumento de avaliação que tem como função o arquivamento de registros realizados no decorrer de um projeto de trabalho, neste caso um semestre e um componente curricular, no qual são organizadas as produções (textos, imagens, comentários, resumos, etc), capazes de nortear ações que fomentem o desenvolvimento do grupo (AMBRÓSIO, 2013).

O portfólio pode ser definido como um "continente de diferentes classes de documentos" (HERNÁNDEZ, 1998, p. 100), que podem ser organizados em formatos físicos (cadernos, pastas, caixas, bolsa ou álbum) ou digitais (cd-room, blogs, pen-drives, homepage) (MENA, 2018), permitindo o acompanhamento dos avanços e dificuldades dos alunos, bem como auxiliando no planejamento das ações pedagógicas do professor.

Vários estudos ressaltam o papel do portfólio como uma possibilidade de instrumento formativo, entre os quais Hoffmann (2001), Ambrósio (2013), Vieira (2006), Villas Boas (2001). Tais discussões apontam o potencial do instrumento para o acompanhamento contínuo das aprendizagens, para o desenvolvimento da autonomia dos alunos, bem como para o processo de autoavaliação do professor sobre seu próprio trabalho, permitindo o crescimento constante como profissional e a perspectiva de formação conforme o tempo de aprendizagem de cada aluno.

Dessa forma, considerando a importância da vivência de uma prática avaliativa formativa, mediada por portfólio, o presente estudo visa identificar a menção a concepções de avaliação da aprendizagem mediadas por portfólio no Projeto Pedagógico de Curso e analisar a experiência dos professores em formação com a avaliação formativa mediada pelo portfólio. Espera-se que este estudo possa contribuir com a formação de professores reflexivos.

\section{Caminhos metodológicos percorridos}

ISSN 2526-2882 
A metodologia foi construída a partir da abordagem qualitativa, fundamentada na Antropologia e na Sociologia, fortemente divulgadas pela Escola de Chicago nas décadas de 1920 e 1930. Caracteriza-se como um conjunto de práticas materiais e interpretativas que dão visibilidade ao mundo, influenciado pela história pessoal, pelo gênero, classe social, raça, ou seja, o que diferencia as pessoas que fazem parte do contexto (DENZIN, 2006).

Na visão de Engers (1994, p. 68), a pesquisa, a partir do paradigma qualitativo, "penetra no mundo pessoal dos sujeitos, buscando a compreensão, o significado particular da ação das pessoas e utiliza como critério a evidência do acordo intersubjetivo no contexto educacional".

Segundo Minayo (1994, p. 21), “a pesquisa qualitativa trabalha com o universo de significados, motivos, aspirações, crenças, valores e atitudes, o que corresponde a um espaço mais profundo das relações, dos processos e dos fenômenos que não podem ser reduzidos à operacionalização de variáveis”.

Os dados foram coletados em duas etapas. Na primeira realizou-se o estudo do Projeto Pedagógico do Curso (PPC) para compreender como a avaliação formativa e a utilização do portfólio permeiam o texto que regulamenta legalmente e pedagogicamente o curso. $\mathrm{Na}$ segunda analisou-se o questionário respondido por onze acadêmicos, com o propósito de compreender as concepções dos licenciandos acerca do portfólio, das possibilidades e das fragilidades na formação de professores. Salienta-se que na disciplina de Práticas Pedagógicas VII, ministrada no primeiro semestre de 2018, o portfólio é utilizado como instrumento de organização e sistematização das reflexões incitadas por diversas atividades.

Para análise dos resultados, foi utilizado a “Análise de Conteúdo" proposta por Bardin (1977) a partir de três etapas: (1) pré-análise, (2) exploração do material e (3) tratamento dos resultados.

Na pré-análise organizou-se o material a ser analisado com o intuito de torná-lo operacional. Na exploração do material codificaram-se os questionários com caracteres alfanuméricos A1, A2, A3,... A11, respectivamente, sendo a letra "A" relacionada à palavra acadêmico e o numeral uma maneira de identificação para substituir o nome. As respostas de cada atividade analisada foram transcritas fielmente, sintetizadas em trechos e frases, até emergirem duas categorias-chave, conforme Tabela 1:

Tabela 1: Categorias e subcategorias analisadas 
Com a Palavra o Professor, Vitória da Conquista (BA), v.4, n.10, setembro-dezembro / 2019

\begin{tabular}{|c|l|l|}
\hline \multicolumn{1}{|c|}{ Categoria } & \multicolumn{1}{|c|}{ Subcategoria } & \multicolumn{1}{c|}{ Descrição } \\
\hline $\begin{array}{l}\text { Projeto Político } \\
\text { Pedagógico }\end{array}$ & - & $\begin{array}{l}\text { Identifica menções às concepções de avaliação da } \\
\text { aprendizagem mediadas por portfolio no Projeto } \\
\text { Pedagógico de Curso das Ciências da Natureza. }\end{array}$ \\
\hline \multirow{5}{*}{$\begin{array}{l}\text { Experiência dos } \\
\text { Licenciados }\end{array}$} & Concepção & $\begin{array}{l}\text { Compreensão conceitual dos licenciandos sobre } \\
\text { portfólio. }\end{array}$ \\
\cline { 2 - 3 } & Acompanhamento & $\begin{array}{l}\text { Compreensão se as atividades devem ser } \\
\text { acompanhadas pelo professor, aluno ou ambos, em } \\
\text { curtos espaços de tempo ou não. }\end{array}$ \\
\cline { 2 - 3 } & $\begin{array}{l}\text { Compreensão sobre a organização das atividades que } \\
\text { compõem um portfólio, classificadas em direcionadas, }\end{array}$ \\
\cline { 2 - 3 } & Aplicabilidade & $\begin{array}{l}\text { Viabilidade da aplicabilidade do portfólio no Ensino } \\
\text { de Ciências da Natureza. }\end{array}$ \\
\cline { 2 - 3 } & $\begin{array}{l}\text { Possibilidades e } \\
\text { limitações }\end{array}$ & $\begin{array}{l}\text { Desafios e possibilidades que tiveram na construção } \\
\text { do portfólio. }\end{array}$ \\
\hline
\end{tabular}

Fonte: Autores (2017)

Por fim, os resultados foram submetidos ao tratamento das informações, onde foram elaborados quadros e esquemas que condensam e sintetizam as informações fornecidas para análise. A inferência e a interpretação dos resultados são apresentadas a seguir.

\section{Projeto Político Pedagógico: delimitações sobre avaliação formativa}

A Universidade Federal do Pampa - UNIPAMPA, organizada em uma estrutura multicampi 10 (dez) campi, é criada a partir da reivindicação da comunidade da região da Campanha Gaúcha, mobilizada pelo movimento político de expansão das instituições federais de Ensino Superior, promovida pelo Governo Federal, no ano de 2008.

Dom Pedrito é um dos dez campi, no qual funcionam cinco cursos de graduação: Bacharelado em Enologia, Zootecnia, Tecnologia em Agronegócio, Licenciatura em Educação do Campo e Licenciatura em Ciências da Natureza, tendo este último o ingresso de sua primeira turma em 2012.

De acordo com Bierhalz, Araújo e Lima (2013) o curso de Licenciatura em Ciências da Natureza do Campus Dom Pedrito da Unipampa propõe uma formação que habilita o licenciando a atuar no ensino de Ciências da Natureza tanto no Ensino 
Fundamental como no Ensino Médio, justificado pelo viés da interdisciplinaridade e pretende "estimular os alunos em sua curiosidade científica, incentivando-os à pesquisa e a reflexão ética perante a sociedade e a natureza, diante da perspectiva de aproveitamento das potencialidades locais para o desenvolvimento sustentável” (PPC, 2014, p. 18).

Em relação a organização curricular prevê quatro eixos: Formação pedagógica, Universo, Vida na Terra e Tecnologias e desenvolvimento sustentável, os quais suscitam questões problematizadoras ou temas. Em relação a avaliação, o PPC (2014) a compreende como o "processo ensino-aprendizagem que deverá ocorrer de forma contínua e cumulativa, a partir do conhecimento sistematizado, de competências e habilidades desenvolvidas pelo aluno”. (PPC, 2014, p.33), totalmente de acordo com o previsto no artigo 24 da Lei de Diretrizes e Bases da Educação Nacional (LDBN 9394/96) quando aponta como critérios da verificação escolar a questão da continuidade e cumulatividade do desempenho do aluno, com prevalência dos aspectos qualitativos sobre os quantitativos e dos resultados ao longo do período sobre os de eventuais provas finais. (BRASIL,1996)

Na tabela 2 apresentam-se os componentes do curso que mencionam em suas ementas aspectos relacionados à avaliação:

Tabela 2: Relação de Componentes/Semestres e Ementas voltadas a avaliação da aprendizagem

\begin{tabular}{|l|l|l|}
\hline Componente Curricular & $\begin{array}{c}\text { Seme } \\
\text { stre }\end{array}$ & \multicolumn{1}{|c|}{ Aspecto relacionado à avaliação na ementa } \\
\hline $\begin{array}{l}\text { História e Filosofia da } \\
\text { Educação(30h) }\end{array}$ & 2 & $\begin{array}{l}\text { Diferentes tipos de conhecimento respeitando uma linha } \\
\text { histórica, percebendo produção, formas e estratégias de } \\
\text { avaliação }\end{array}$ \\
\hline $\begin{array}{l}\text { Práticas Pedagógicas: } \\
\text { Experimentação em } \\
\text { Educação em Ciências (6oh) }\end{array}$ & 3 & Avaliação de aprendizagem. \\
\hline $\begin{array}{l}\text { Didática, Currículo e } \\
\text { Planejamento(3oh) }\end{array}$ & 4 & $\begin{array}{l}\text { Estratégias de ensino, seleção de conteúdos e formas de } \\
\text { avaliação, Planejamento e avaliação da aprendizagem }\end{array}$ \\
\hline $\begin{array}{l}\text { Políticas deas, } \\
\text { Legislação e Gestão da } \\
\text { Educação Básica (45h) }\end{array}$ & 5 & $\begin{array}{l}\text { Avaliação do PPP; As teorias e práticas da avaliação escolar; } \\
\text { Escolha de estratégias, de critérios e formas de avaliação } \\
\text { para a prática nas escolas de Ensino Fundamental e Médio. }\end{array}$ \\
\hline $\begin{array}{l}\text { Práticas Pedagógicas:Temas } \\
\text { Estruturadores para o } \\
\text { Ensino de Ciências (6oh) }\end{array}$ & 5 & $\begin{array}{l}\text { Análise do papel dos recursos didáticos e da avaliação no } \\
\text { ensino básico em relação aos temas estruturadores. }\end{array}$ \\
\hline
\end{tabular}




\begin{tabular}{|l|l|l|}
\hline $\begin{array}{l}\text { Práticas Pedagógicas: } \\
\text { formação docente e } \\
\text { avaliação(6oh) }\end{array}$ & 7 & $\begin{array}{l}\text { Concepções de avaliação e suas implicações no processo de } \\
\text { ensino e aprendizagem; Caracterizar as funções de } \\
\text { avaliação reconhecendo sua importância da tomada de } \\
\text { decisão. As diferentes modalidades de avaliação e os } \\
\text { princípios de avaliação; Etapas de avaliação. Professor e a } \\
\text { avaliação do rendimento escolar; Os objetivos e seu papel } \\
\text { na avaliação da aprendizagem; Discussão e reflexão sobre o } \\
\text { processo de avaliação escolar. }\end{array}$ \\
\hline $\begin{array}{l}\text { Estágio Curricular } \\
\text { Supervisionado II (3oh) }\end{array}$ & 7 & Análise, reflexão e avaliação da aula desenvolvida. \\
\hline
\end{tabular}

Fonte: Autores (2017)

A licenciatura é organizada em nove semestres, com aulas de segundas a sextas no turno da noite e no sábado pela manhã. Das 52 disciplinas obrigatórias da grade curricular, que totalizam 2430 horas, oito possuem em suas ementas relação direta com temas relacionados à avaliação da aprendizagem (tabela 1), perfazendo um total de aproximadamente 15\% no que tange aos componentes e 10\% no que tange a carga horária. Esta informação possibilita afirmar que no PPC a avaliação da aprendizagem está sinalizada como uma discussão que perpassa a formação dos professores de Ciências da Natureza.

A análise também demonstra que a familiarização dos licenciandos com o assunto ocorre no segundo semestre, na disciplina intitulada História e Filosofia da Educação, onde consta na ementa: "o estudo de diferentes tipos de conhecimento respeitando uma linha histórica, percebendo produção, formas e estratégias de avaliação”(PPC, 2014). Ao longo do curso, as discussões se ampliam permeando a disciplina de Didática (4 semestre), Políticas Públicas (5 semestre), Práticas Pedagógicas (3, 4 e 5 semestres) e Estágio Supervisionado II (7 semestre).

Quando se busca elementos textuais no PPC relacionados aos diferentes instrumentos de avaliação utilizados no processo avaliativo dos futuros professores, constata-se que são eles:

Observações através da interação professor-alunos, questões orais solicitadas aos alunos, estudos de caso para análise e proposição de resultados, atividades práticas e relatórios escritos, respostas escritas a questões sobre o conteúdo, textos produzidos pelo aluno e apresentação de seminários, entre outras. (PPC, 2014, p.33).

Não existe uma menção sobre a utilização de portfólios como instrumentos avaliativos ao longo do texto do PPC, no entanto este instrumento é explorado em pelo menos dois Componentes Curriculares: Estágio Supervisionado II (apêndice ao PPP- planilha de acompanhamento do estagiário) e Práticas Pedagógicas VII.

A discussão sobre o portfólio como um instrumento formativo na Licenciatura justifica-se nas concepções de Freire (2003) e Villas-Boas (2006, p. 114) para quem o portfólio caracteriza-se como "um dos saberes a serem incorporados por futuros profissionais de 
educação, que, por meio dele, não apenas estudam sobre a avaliação, como normalmente se procede, mas vivenciam práticas que poderão adaptar nas escolas onde atuarão". Trabalha-se assim a teoria e a prática de avaliação numa perspectiva emancipadora. Já para Freire (2003, p. 54): "a reflexão tece o processo de apropriação da prática e da teoria. Somente tendo a teoria nas mãos, o educador questiona e recria outras teorias."

Torna-se significativo destacar que a utilização do portfólio no ensino superior já é tema de pesquisa, exemplificado pelo trabalho de Vieira (2006), que aborda a utilização de portfólios em cursos superiores e, baseando-se nas representações sociais sobre avaliação de 178 licenciandos de oito cursos de uma Universidade de Minas Gerais, investigou, por meio de dois questionários, se o uso do portfólio vem modificando as formas de pensar avaliação, na formação de professores. Entre as conclusões, destacou a necessidade de aprofundamento sobre as questões de avaliação, englobando o estudo do portfólio como instrumento.

Para fins da construção de uma avaliação formativa, torna-se importante lembrar das palavras de Luckesi (2011, p. 72) que, ao discutir sobre as questões de diferenciação entre examinar versus avaliar, ressalta a necessidade de exercitar permanentemente um propósito antes do contato com os alunos: "nunca mais atuarei com atos examinativos em minha sala de aula”.

\section{A experiência dos professores em formação com a avaliação formativa: portfólio}

Quando questionados sobre a experiência prévia com o portfólio, sete licenciandos (64\%) afirmaram não conhecer, bem como não ter utilizado em outras ocasiões e quatro (36\%) declararam já ter utilizado, sendo que destes dois relacionaram a experiência ao Programa Institucional de Bolsas de Iniciação à Docência (PIBID), evidenciado pelo trecho: "Utilizei no Pibid, não era especificamente sobre avaliação, mas em alguns momentos usávamos para anotar as observações” (A1).

A partir de tais narrativas, percebeu-se a pouca experiência dos alunos em relação à construção de portfólios, bem como os conceitos que esse instrumento engloba no âmbito da avaliação.

Aliado a este fator, na subcategoria concepção do portfólio, os licenciandos foram questionados a respeito da compreensão conceitual do instrumento, sendo que seis acadêmicos $(54,5 \%)$ o caracterizaram como formativo e um número considerável $(45,5 \%)$ o consideraram como classificatório. Por outro lado, 10 (91\%) destacaram que favorece a autonomia, autorreflexão e autoavaliação. Esta contradição revela que o portfólio pode não ter alcançado seu objetivo com a turma, pois parece que foi mais um instrumento avaliativo. Este indicador merece estudos futuros, aprofundando as questões referentes às concepções de avaliação construídas pelos alunos do ensino superior e a quais as características são 
relacionadas a cada uma delas.

De acordo com Neves, Guerreiro e Azevedo (2016), o portfólio tem sido apontado como um facilitador para o desenvolvimento da avaliação formativa, já a Association for Supervision and Curriculum o indica como um dos três melhores métodos de ensino e aprendizagem. Para Perrenoud (1999), a avaliação formativa caracteriza-se por tornar-se um elemento determinante na prática educativa, buscando sua continuidade e a regulação da ação pedagógica, inscrevendo-se através da observação dos efeitos desta ação e modificando-a para melhor atingir os objetivos.

Hadji (2001, p. 19) destaca que a avaliação é formativa quando "situa-se no centro da ação de formação (...) porque sua função principal é contribuir para uma boa regulação da atividade de ensino. Trata-se de levantar informações úteis à regulação do processo de ensino/aprendizagem".

Hoffmann (2014) destaca que o portfólio configura-se como um instrumento da avaliação formativa na medida em que considera todo o processo de construção do conhecimento, levando em consideração os saberes prévios dos educandos e buscando superar as falhas identificadas no processo de ensino e de aprendizagem. Conforme corrobora Vilarinho e outros (2017) esse instrumento proporciona a reflexão, avaliação e autoavaliação durante os percursos da aprendizagem, fortalecendo o vínculo entre professores e estudantes.

Ainda reforçando a importância do portfólio no desenvolvimento humano através da auto avaliação, destaca-se a concepção de Grilo e Machado (2005).

O portfólio conduz a um uso sistemático do texto narrativo enquanto documentário do eu que (...) não só promove o desenvolvimento do formando a partir das suas próprias experiências, motivações e necessidades como contribui para a sua autoavaliação e o seu autoconhecimento. O que significa que o processo de elaboração do portfólio incita o educador a analisar não só os seus pontos fortes, como também as suas debilidades. (GRILO E MACHADO. 2005, p.31)

Na subcategoria organização do portfólio, utilizou-se como base teórica o descrito por Mena (2018), ao sugerir que a sua construção segue três padrões: direcionada, na qual apenas o professor estabelece critérios de inclusão de atividades no portfólio; livre construção, ou seja, o aluno estabelece os critérios de inclusão de atividades no portfólio; ou mista, onde os critérios são estabelecidos por ambos os sujeitos.

A partir das respostas dos licenciandos, constatou-se que cinco licenciandos $(45,5 \%)$ compreendem que a escolha das atividades do portfólio devem ser direcionadas pelo professor e de caráter obrigatório para o aluno. Nesse tipo de organização, geralmente, o docente sentese inseguro em deixar todo o processo por conta do aluno e aos poucos o incentiva a expressarse com maior liberdade, desenvolvendo aos poucos sua independência (NEVES, GUERREIRO 
\& AZEVEDO, 2016), a insegurança também é uma característica do aluno que neste processo não sabe ao certo o que registrar.

Por outro lado, três (27\%) acreditam na livre construção, ou seja, o aluno tem completa autonomia sobre suas formas de expressão, é responsável pelas escolhas, pela elaboração dos trabalhos que melhor representam suas formas de aprender. Nesta forma de construção, entende-se necessário o desenvolvimento da independência do aluno para melhor lidar com as características próprias de seu processo de aprendizagem de forma honesta e crítica, com o distanciamento necessário para encontrar falhas e sensibilidade suficiente para respeitar seus processos individuais.

Araujo e Alvarenga (2006) analisaram as reflexões registradas nos portfólios dos estudantes de um curso superior de formação de professores, observaram a influência das atividades propostas, pois desafiam o registro através de diferentes expressões, sendo que cada atividade proposta desenvolve determinadas habilidades, bem como possibilita reunir informações sobre como o aluno a desenvolve, delimitando quando os ajustes são necessários, sempre com o objetivo de promover a continuidade das múltiplas aprendizagens.

Por fim, a análise demonstra que três licenciandos (27\%) apontam o formato de construção misto como o ideal, na qual são integradas às atividades estabelecidas tanto pelo professor como pelos acadêmicos. Dessa forma, entende-se a necessária troca entre professor e aluno para o equilíbrio da relação pedagógica, entretanto, é preciso atentar que cada forma de acompanhamento diz respeito a uma proposta e um momento único do processo de ensino e aprendizagem e que este pode ocorrer em caráter de maior ou menor independência por parte do aluno.

Em relação aos aspectos de acompanhamento do portfólio, três respostas foram indiferentes (27\%), enquanto quatro (36\%) responderam que esta não é uma responsabilidade apenas do professor, mas também do aluno, fator que corrobora o conceito de autoavaliação, processos de reflexão crítica sobre a própria prática (HOFFMANN, 2001). A autoavaliação é um processo que deve ser instigado no desenvolvimento da avaliação e para tanto, torna-se necessário fomentar a autonomia dos estudantes sobre suas formas de aprender.

Por outro lado, quatro respostas (36\%) apontaram que apenas o professor deve ter a responsabilidade de acompanhamento da construção do portfólio, o que converge para situações iniciais de avaliação formativa, onde o aluno ainda não possui autonomia suficiente para refletir sobre os diferentes aspectos da própria aprendizagem.

Salienta-se que sete (64\%) acreditam que o acompanhamento das atividades devem ser em curtos espaços de tempo. De acordo com Hoffmann (2014), a avaliação formativa implica em acompanhar individual e continuamente o processo de ensino e aprendizagem. Para tanto, algumas estratégias pedagógicas podem auxiliar nesse processo, tais como: 
observações esporádicas, intuitivas e de caráter não intencionais e/ou atividades programadas pelo professor. Quanto mais frequente for estas ações, mais eficaz será o acompanhamento do processo de ensino e aprendizagem.

Dessa forma, entende-se que os acompanhamentos e a avaliação do portfólio podem ser processos conjuntos, de maneira que o professor perceba os objetivos alcançados em relação àqueles inicialmente almejados, refletindo sobre suas formas de aprender e aprimorar gradativamente a expressão desse aprendizado (MENA, 2018).

$\mathrm{Na}$ subcategoria aplicabilidade, dez acadêmicos (91\%) consideraram viável a utilização do portfólio no Ensino de Ciências na Educação Básica. Dentre as justificativas, citaram que esse instrumento avaliativo possibilita a organização, sistematização e feedback das atividades, conformes excertos a seguir: "[...] é um recurso que possibilita voltar à estudos anteriores” (A2); “[...] dá para voltar atrás e rever conceitos (A3); “[...] serve como suporte para os registros diários” (A11); “[...] pode cativar o estudante e aproximá-lo da leitura”(A1).

Para Zeferino, Domingues e Amaral (2007, p. 177), feedback “[...] refere-se à informação dada ao aluno que descreve e discute seu desempenho em determinada situação ou atividade”. Essa ferramenta desenvolve conscientização da aprendizagem, pois motiva o licenciando a refletir, repensar e reformular determinado resultado. Sua ausência pode levar a interpretação inadequada ou equivocada do desempenho, gerando falsa confiança ou medo do erro.

Além disso, o A5 considera que "[...] seja dificil, mas não impossível de aplicar um portfólio, pois exige planejamento". Este pensamento é corroborado por Nascimento (2015) e Stoll (2017), que afirmam que o portfólio ainda é um instrumento de avaliação pouco utilizado, pois, exige do educador tempo para realização do planejamento e correção das atividades.

Destaca-se que oito (73\%) acreditam que devem ser aplicadas as mesmas atividades do portfólio para todos os alunos e três (27\%) conforme as necessidades de aprendizagem de cada um. Para Freire (2011), os estudantes são por natureza diferentes em suas particularidades, vivências e experiências. Logo, as atividades, testes e tarefas também devem ser planejados e elaborados de acordo com a particularidades individuais (HOFFMANN, 2014).

Na subcategoria aplicabilidade considerando os níveis de ensino, dez sujeitos (91\%) acreditam que o portfólio seria melhor utilizado na Educação Básica. Destes, cinco (45,5\%) citaram o Ensino Fundamental, três (27\%) o Ensino Médio e dois (18,5\%) ambos. Apenas um (9\%) mencionou o Ensino Superior. Tais resultados contrariam o referencial teórico, que afirma que a maior parte das pesquisas da área da Educação sobre a temática vêm sendo desenvolvida no âmbito do Ensino Superior (MENA, 2018).

Além disso, nove (82\%) utilizariam o portfólio nas Ciências da Natureza (Biologia, 
Química e Física) e dois (18\%) talvez. Tal resultado demonstra a aceitabilidade desse instrumento pelos licenciandos e a possibilidade da inserção na prática docente.

Na subcategoria possibilidades e limitações do portfólio, cinco (45,5\%) destacaram que refletir através da escrita foi a maior dificuldade que tiveram na construção desse instrumento, na Componente Curricular analisada, conforme evidenciado nos excertos a seguir: "[...] às vezes se torna difícil tu expor tuas ideias na escrita” (A1); "[...] pensamos de uma maneira e ao transcrever muda à ideia principal, ou seja, faltam leituras para aprimorar a escrita" (A3).

Neste contexto, torna-se importante salientar o que enuncia Hoffmann (2001, p. 165), ao discutir sobre o princípio fundamental da expressão do conhecimento

O que ouvimos, vemos ou lemos não é o pensamento do aluno, mas a sua expressão, que também evolui, se aprimora, precisa ser trabalhada. [...] Aprendemos e sentimos muito mais e de jeito diferente do que o expressamos. Assim, é preciso analisar as manifestações dos alunos absorvendo as duas dimensões: a interpretação de seus entendimentos e da forma de expressão de tais entendimentos, direcionando o trabalho pedagógico nas duas dimensões (HOFFMANN, 2001, p. 165).

De acordo com Kish e outros (1997), a escrita reflexiva melhora a capacidade organizacional, argumentativa e crítica. Três licenciandos (27\%) destacaram que foi difícil se expressar de forma criativa. Villas Boas (2006) salienta que a utilização de outras formas de expressão na construção do portfólio estimula a participação dos alunos nas atividades e a diversidade revela potencialidades e capacidades que ultrapassam à linguagem escrita.

Três (27\%) citaram como limitação a dificuldade da realização de atividades coletivas e o tempo, conforme trechos: "a maior dificuldade é termos o auxílio da turma, ou seja os alunos colaborarem para as atividades” (A6), “[...] o curto tempo em sala de aula, pois limita o professor na utilização desse recurso" (A11).

Perrenoud (1995) chama a atenção para o desafio tanto para os alunos como para os professores incorporarem novas formas de aprender e ensinar, poissempre que uma nova abordagem teórico-metodológica é introduzida, os ofícios são redefinidos. Tanto o portfólio com qualquer outro instrumento que fuja do padrão, exige disponibilidade, envolvimento, superação de resistências, construção conjunta e transparência no processo.

\section{Algumas considerações sobre o percurso}

Analisar as concepções dos licenciandos acerca dos processos avaliativos mediados pelo portfólio e as possibilidades de ressignificação das práticas na formação inicial torna-se um desafio, pois é preciso considerar que a realidade investigada é apenas um recorte de uma totalidade ampla e complexa, bem como cabe ressaltar as limitações dos pesquisadores, que 
representam apenas um olhar, que tem origem em estudos iniciais, dessa forma em nenhum momento nos propomos a absolutizar a discussão.

Cabe ressaltar que assim como Vale (1997) consideramos a formação inicial um período de formação privilegiado, na medida em que são desenvolvidos conhecimentos teóricos e práticos, não só no sentido de reprodução mas também no sentido crítico de escolher caminhos próprios, fortalecendo a docência reflexiva, respeitando as características e diferenças de cada sujeito e de cada contexto.

O espaço de construção identitária vivida na Licenciatura não é um espaço seguro, unificado e acabado. Ao contrário, é um território de disputa, de contestação, de repressão, no qual diferentes representações sociais, culturais, pedagógicas colaboram para definições a respeito de quem somos, quem queremos ser e quem podemos nos tornar.

No processo avaliativo, neste caso mediado pelo portfólio, o sujeito converte-se como objeto principal do saber, emerge como pessoa distinta e única, que se revela na ação e no discurso, se constitui no processo. Conforme Hall (2003, p.38) "a identidade é realmente algo formado ao longo do tempo, através dos processos, e não algo inato", e todas as possibilidades de reflexão contribuem para este entendimento de inacabamento.

As concepções dos licenciandos possibilitaram concluir que a construção dos portfólios contribuiu para o surgimento de novas formas de pensar sobre si próprio e o sobre seu entorno, pois a avaliação mediada por esse instrumento caracterizou-se como um espaço de expressão, nos quais tinham liberdade para registrar desejos, medos, obstáculos, avanços na sua trajetória, além da possibilidade da reflexão e do autoconhecimento. Também revela as marcas de uma formação alicerçada na racionalidade técnica, pela dificuldade de aceitarem protagonizar o processo de construção do portfólio, entenderem que o professor deve determinar o que, quando e como fazer. Aspectos relevantes para serem rediscutidos com o grupo da pesquisa.

Este estudo demonstrou possibilidades de desenvolvimento de processos de avaliação formativa, mediados pelo portfólio, favorecendo a ampliação da autoavaliação no contexto da formação de professores. Assim, a partir do desenvolvimento de reflexões e tomada de consciência do futuro docente sobre suas formas de pensar sobre avaliação torna-se possível refletir sobre a prática avaliativa que irão desenvolver no exercício da docência.

\section{Referências}

AMBrósIO, M. O Uso do Portfólio no Ensino Superior. Petrópolis: Vozes, 2013.

BARDIN, L. Análise de Conteúdo. Lisboa: Edições 70, 1977.

BRASIL. Lei de diretrizes e Bases da Educação Nacional. Ministério da Educação. 1996. ARAUJO, Z. R.; ALVARENGA, G. M. Portfólio: Uma alternativa para o gerenciamento das 
situações de ensino e aprendizagem. Estudos em Avaliação Educacional, São Paulo, v. 17, n. 35, p. 187-210, set./dez. 2006.

BIERHALZ, C. D. K.; ARAUJO, R. R. de; LIMA, V. de A. Licenciatura Interdisciplinar em

Ciências da Natureza: Análise do Projeto Pedagógico de Curso. In: Anais. SIIEPE - Simpósio Internacional sobre Interdisciplinaridade no Ensino, na Pesquisa e na Extensão - Região Sul. Universidade Federal de Santa Catarina, 2013. Disponível em: https://pt.scribd.com/document/209883374/Bierhalz-et-al-Licen ciaturaInterdisciplinar-em-Ciencias-da-Natureza, acesso em $18 \mathrm{Jul} .2017$.

CONNELY F. Michael y CLANDINININ D. Jean. Relatos de experiência e investigação narrativa. In: LARROSA, Jorge (org). Déjame que te cuente: ensayos sobre narrativa y education. Barcelona. Editorial Laertes, 1995, p.11/59.

DENZIN, N. K. O planejamento da pesquisa qualitativa: teorias e abordagens. Porto alegre: Artmed, 2006.

ENGERS, M. E. A, Paradigmas e metodologias de pesquisa em Educação; notas para reflexão. Porto Alegre; EDIPUCRS, 1994.

FREIRE, P. Pedagogia do Oprimido. 9a ed. Rio de Janeiro: Paz e Terra, 1981.

FONSECA, E. M.; BIERHALZ, C. D. K. Discutindo articulações entre ensino de Ciências e Educação do Campo através da análise dos cadernos. Revista Brasileira de Educação do Campo, Tocantinópolis, v. 1, n. 2, p. 255-278, 2016.

GRILO, J. \& MACHADO, C. Portfolios Reflexivos na Formação Inicial de Professores de Biologia e Geologia: Viagens na Terra do Eu. In Sá-Chaves, I. (Coord.) (2005). Os "Portfolios" Reflexivos (Também) Trazem Gente Dentro: reflexões em torno do seu uso na humanização dos processos educativos. Porto. Porto Editora, 2005 .

HADJI, C. Avaliação Desmistificada. Porto Alegre: ARTMED, 2001.

HALL, Stuart. A Identidade Cultural na Pós-Modernidade. Rio de Janeiro: DP \& A Editora; 1997.

HERnÁNDEZ, F. Cultura Visual, Mudança Educativa e Projeto de Trabalho. Porto Alegre: Artes Médicas Sul, 2000.

. Transgressão e Mudança na Educação: os projetos de trabalho. Porto Alegre: ArtMed, 1998.

HOFFMANN, J. Avaliar para Promover: as setas do caminho. 15. ed. Porto Alegre: Mediação, 2001.

LUCKESI, C. C. Avaliação da Aprendizagem Escolar: estudos e preposições. 19. ed. São Paulo: Cortez, 2008.

MARTINEZ, C. L.P. Formação de Professores e Avaliação Formativa: análise de um ISSN 2526-2882 
projeto de interação universidade-escola. Tese. Faculdade de Ciências da Universidade Estadual Paulista Julio de Mesquita Filho, Bauru: São Paulo, 2009.

MENA, L. P. Estudo exploratório sobre Portfólio como instrumento de avaliação. 2018. 65 f. Monografia (Licenciatura em Ciências da Natureza) - Universidade Federal do Pampa, Dom Pedrito, 2018.

MINAYO, M. C. S. Pesquisa social: teoria, método e criatividade. Petrópolis: Vozes, 2011.

NASCIMENTO, L. A. L. Qual a medida da sua avaliação? construindo um portfólio de avaliação no ensino de ciências. 2015. 145 f. Dissertação (Mestrado Profissional em Ciências) - Instituto Federal de Educação, Ciência e Tecnologia do Rio de Janeiro, Nilópolis, Rio de Janeiro, 2015.

NEVES, A. S. C.; GUERREIRO, J. M. A.; AZEVEDO, G. R. Avaliando o Portfólio do Estudante: uma contribuição para o processo de ensino-aprendizagem. Avaliação, Sorocaba, SP, v. 21, n. 1, p. 199-220, mar. 2016.

PERRENOUD, P. Avaliação: da excelência à regulação das aprendizagens - entre duas lógicas. Porto Alegre: Artes Médicas, 1999.

UNIVERSIDADE FEDERAL DO PAMPA. Campus Dom Pedrito. Projeto Político Pedagógico (PPC) do Curso de Licenciatura em Ciências da Natureza. Disponível em: <http://dspace.unipampa.edu.br/bitstream/riu/110/3/PPC_Ci\%C3\%AAnciasdaNat urezaDomPedrito_2015.pdf>. Acesso em: 10 Set 2016.

VIEIRA, V. M. O. Representações Sociais e Avaliação Educacional: o que revela o portfólio. 2006, 261 f. Tese (Doutorado em Psicologia da Educação) - Pontifícia Universidade Católica de São Paulo, São Paulo, 2006.

VILlAS BOAS, B. M. Portfólio: Avaliação e trabalho pedagógico. Campinas: Papirus, 2006. . Contribuições do Porta-fólio para a Organização do Trabalho Pedagógico.

Estudos em Avaliação Educacional, n. 23, jul-jun/2001, p. 137-152.

STOLL, V. G. O Portfólio como Instrumento Didático-Metodológico no Processo Avaliativo de Ciências da Natureza na Educação de Jovens e Adultos. 2017. 93 f. Monografia (Licenciatura em Ciências da Natureza) - Universidade Federal do Pampa, Dom Pedrito, 2017.

ZEFERINO, A. M. B.; DOMINGUES, R. C. L.; AMARAL, E. Feedback como estratégia de aprendizado no ensino médio. Revista Brasileira de Educação Médica [online], v. 31, n. 2, p. 176-17, 2000. 


\section{Biografia Resumida}

Crisna Daniela Krause Bierhalz: Graduação em Pedagogia pela Universidade Federal de Pelotas, Doutora em Educação pela Universidade Católica do Rio Grande do Sul (PUC). Professora Adjunta da Universidade Federal do Pampa (UNIPAMPA, Dom Pedrito, RS).

Contato: crisnakrause@gmail.com

Link Lattes: http://lattes.cnpq.br/8524665688345631

Liziane Padilha Mena: Graduação em Ciências da Natureza Licenciatura pela Universidade Federal do Pampa (UNIPAMPA). Estudante do Programa de Pós-Graduação Mestrado Acadêmico em Ensino da Universidade Federal do Pampa (UNIPAMPA, Bagé, RS).

Contato: lizianemena1@gmail.com

Link Lattes: http://lattes.cnpq.br/6451009185605231

Vitor Garcia Stoll: Graduação em Ciências da Natureza Licenciatura pela Universidade Federal do Pampa (UNIPAMPA). Estudante do Programa de Pós-Graduação Mestrado Acadêmico em Ensino da Universidade Federal do Pampa (UNIPAMPA, Bagé, RS).

Contato: vitorgarciastoll@gmail.com

Link Lattes: http://lattes.cnpq.br/8592218192423206 